\title{
Can Er:YAG laser be an alternative to conventional methods for repairing composite resins?
}

\author{
Digdem Eren, DDS, PhD, ${ }^{\text {a }}$ Ozden Ozel Bektas, DDS, PhD, ${ }^{a}$ Seyda Herguner Siso, DDS, PhD,${ }^{\mathrm{b}}$ \\ ${ }^{a}$ Department of Restorative Dentistry, Faculty of Dentisty, Cumhuriyet University, Sivas, Turkey. \\ ${ }^{\mathrm{b}}$ Department of Restorative Dentistry, Faculty of Dentistry, Bezmi Alem University, Istanbul, Turkey.
}

Received: 16 October $2012 \quad$ Accepted: 22 October 2012

\begin{abstract}
Objectives: The objective of this study was to compare the effect of four different surface treatments on the repair bond strength of aged composite resin by employing the micro-shear test.

Material and Methods: Forty-eight composite blocks were prepared. All samples were thermocycled for 1000 cycles between $(5 \pm 2)$ and $(55 \pm 2) \propto \mathrm{C}$ with a dwell time of $30 \mathrm{~s}$ and a transfer time of $5 \mathrm{~s}$. The samples were randomly divided into four groups and were subjected to the following treatments $(n=12)$ : Group 1 - phosphoric acid; Group 2 - diamond bur ; Group 3 - diamond bur+ phosphoric acid; Group 4 - Er:YAG Laser. After the aging procedure, fresh microhybrid resin composite was bonded to the treated surfaces with an etch and rinse adhesive resin. The repair bond strength of each sample was determined using a micro-shear bond strength test. All data were analyzed using the Kruskal Wallis test.

Results: There were no significant differences between all groups $(p<0.05)$.

Conclusions: Based on the results of this study, each of the four surface treatment methods produced sufficient repair bond strength. A proper bonding must be created between the existing aged composite and the new one for successful repair.
\end{abstract}

Keywords: Repair bond strength, composite resin, Er:YAG laser, micro-shear.

\section{INTRODUCTION}

In restorative dentistry, there is a growing trend towards repairing defective resin composite restorations instead of removing and replacing the complete restoration in order to increase its longevity, to save sound tooth structure, and to avoid trauma from restorative procedures. $^{1}$

When doing this procedure, one must ensure there is an adequate surface treatment so that the new composite effectively bonds to aged restorations. Because the number of reactive methacrylate groups is limited after polymerization and water sorption into the

Digdem EREN

Department of Restorative Dentistry,

Faculty of Dentistry,

Cumhuriyet University,

Sivas, Turkey.

Tel: +90346 2191300-2791

Fax: +90346 2191237

e-mail:digdemisin@hotmail.com preexisting composite, ${ }^{2-4}$ various surface conditioning methods have been developed to improve the adhesion of aged and repaired composite resins. Surface treatment protocols include acid etching with hydrofluoric or phosphoric acid, grinding, sandblasting with different types and sizes of particles, and using different types of adhesive resins. ${ }^{5}$ Phosphoric acid is much safer to use than the stronger hydrofluoric acid, and its action is primarily to clean and remove superficial debris and organic films. ${ }^{6-10}$ Diamond burs are most often used to remove old restorations. ${ }^{11}$ However, a disadvantage of using this method is that one cannot selectively remove the material. The cavitary preparation using rotary instruments is painful for the patient, requiring anesthesia in most cases. The patients perceive the Er: YAG laser as being more comfortable than mechanical treatment and it is widely used by many 
dentistry specialists. It has a wavelength of $2940 \mathrm{~nm}$, which is absorbed by the water and also by the hydroxyapatite present on the enamel and dentin. There is general consensus that Er:YAG is one of the best laser types for cavity preparation because of its efficiency, especially in dentin, and there is no danger of pulpal damage if it is used with sufficient water cooling. Er: YAG is also efficient in removing composite restorations. $^{12}$

Clinically, the bonding between two composite layers is achieved in the presence of an oxygen-inhibited layer of unpolymerized resin. $^{13}$ However, aged restorations do not contain an unpolymerized surface layer, so the age of the restoration is an important factor in composite repairs. ${ }^{13-15}$ Researchers performing in vitro studies have used methods such as thermocycling and storage in aqueous media or citric acid to simulate the aging of composites. ${ }^{15,17}$ Thermocycling generates stresses due to the thermal expansion of various materials involved in a restoration, and this could result in bond failure at the site of the tooth restoration or filler-matrix interface. ${ }^{18}$

Other researchers have evaluated different factors affecting composite repair, including surface roughness, ${ }^{19-22}$ intermediate agent applied, ${ }^{20-22}$ and repair material used, ${ }^{23}$ and they have reported divergent results. However, there is little information regarding the effect of Er: YAG laser on the composite repair procedure. The purpose of this study was to do an in-vitro evaluation of the effectiveness of various surface treatments on the micro-shear repair bond strength of composite resin. The null hypothesis was that surface treatment methods influence the repair bond strength of aged composite resins.

\section{MATERIALS AND METHODS}

Forty-eight micromatrix hybrid composite blocks (Esthet $\mathrm{X} \circledast$, Dentsply, Milford, DE) with dimensions of
$4 \mathrm{~mm} \times 4 \mathrm{~mm} \times 1 \mathrm{~mm}$ were obtained using a stainless steel mold that was firmly affixed to a glass slide and filled with a micromatrix hybrid composite and covered with a Mylar strip and another glass slide. The composite was polymerized using a halogen curing unit (Hilux; Benlioglu Dental, Turkey) at an intensity of 500 $\mathrm{mW} / \mathrm{cm}^{2}$ for 40 seconds. During the composite block preparation, the light intensity of the halogen was periodically checked. After its removal from the mold, the lower surface of each composite block was similarly cured for 20 seconds. The exposed test surfaces of the repair groups were wet-polished with 800-grit silicon carbide paper. All samples were stored in distilled water at $37^{\circ} \mathrm{C}$ for 24 hours, then thermocycled for 1000 cycles between $(5 \pm 2)$ and $(55 \pm 2) \circ \mathrm{C}$ with a dwell time of 30 seconds and a transfer time of 5 seconds. After the aging procedure, test samples were randomly distributed into 4 groups $(n=12)$ according to surface treatment procedures.

Group 1 (Acid treatment) : $34 \%$ phosphoric acid ( Dentsplay; De Trey, Germany ) was applied to the aged resin composite surface for $30 \mathrm{~s}$, then washed 30 $\mathrm{s}$ and air dried for $10 \mathrm{~s}$. The surface of acid treated sample was examined under a stereomicroscope (Nikon SMZ800, Tokyo, Japan) at a magnification of $40 \times$ as shown in Figure 1.

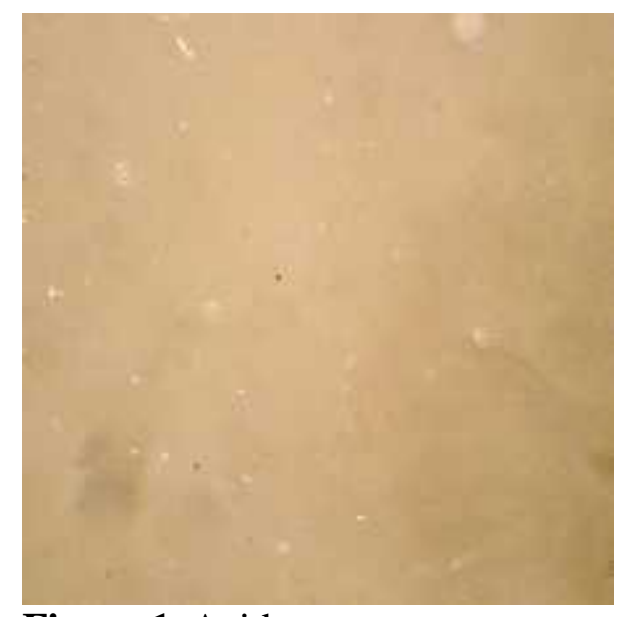

Figure 1. Acid treatment 
Group 2 (Bur treatment): The aged resin composite surface was roughened using 5 strokes with a coarse diamond bur rotating at high speed under a constant water spray. Then, the specimens were rinsed with water and air dried. The bur treatment group sample was shown in Figure 2.

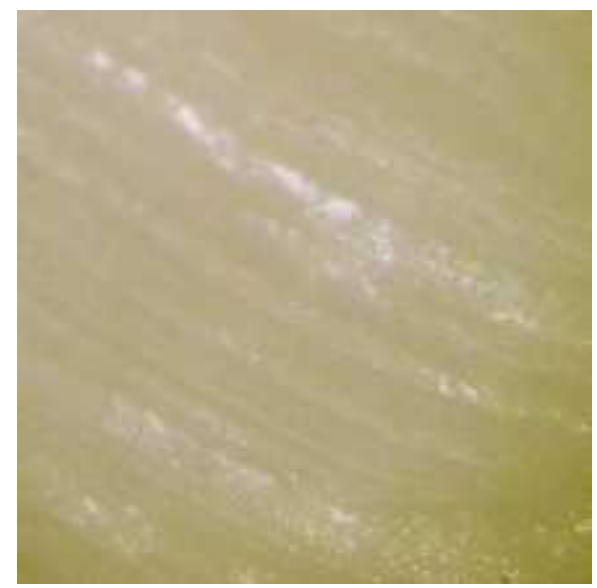

Figure 2. Bur treatment.

Group 3 (Bur + acid treatment) : The aged composite resin surface was roughened with 5 strokes of a coarse diamond bur under a constant water spray; next, a $34 \%$ phosphoric acid solution was applied for $30 \mathrm{~s}$; and finally, it was washed $30 \mathrm{~s}$ and air-dried for $10 \mathrm{~s}$. A new bur was used after every five treatments. The surface of samples under stereomicroscope is shown Figure 3.

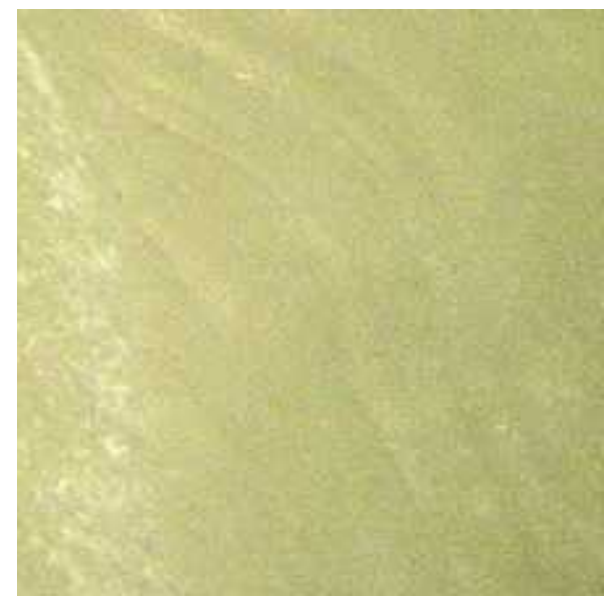

Figure 3. Bur + acid treatment.
Group 4 (Er:YAG laser treatment): The Er:YAG laser (Smart 2940D Plus, Deka Laser; Florence, Italy) was used on the aged resin composite surface. Laser energy was delivered in pulse mode with a wavelength of $2.94 \mathrm{~m}$ at $150 \mathrm{~mJ}, 10 \mathrm{~Hz}$, $1.5 \mathrm{~W}, 0.119 \mathrm{~W} / \mathrm{mm} 2$ and $700-\mathrm{ms}$ pulse duration. The spot size of the laser was 4 $\mathrm{mm}$, and the distance of laser to the composite resin was $10 \mathrm{~mm}$. Water irrigation was used during the lasing of the samples. The surface of the laser was treated under stereomicroscope as shown in Figure 4.

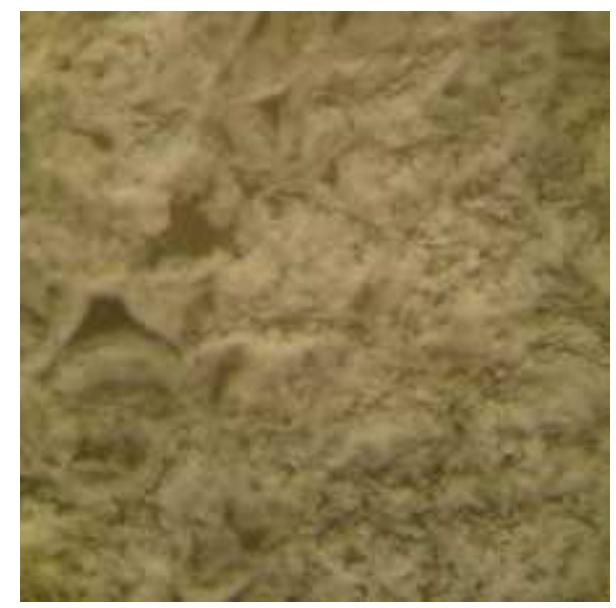

Figure 4. Er:YAG laser treatment.

After surface treatments bonding of applying Prime\&Bond NT (Dentsply, DeTrey; Konstanz, Germany) was applied with a brush to all samples following the manufacturer's instructions. Then, a small piece of polyethylene tube (Tygon, Norton Performance Plastic Co.; Cleveland $\mathrm{OH}$, USA) with an internal diameter of $0.7 \mathrm{~mm}$ and a height of $1 \mathrm{~mm}$ was firmly placed on the uncured resin, and the adhesive resin was light cured for 20 seconds. A microhybrid resin composite (Filtek Supreme, 3M, ESPE; St. Paul, MN, USA) was placed into the bonded tube and light cured with the halogen curing light for 40 seconds. The specimens were left in water at room temperature for one hour. Then the tygon tube was removed. 
After storage in $37^{\circ} \mathrm{C}$ water for 24 hours, the samples were attached to the testing device (Bencor Multi-T, Danville Engineering Co.; San Ramon, CA, USA) with a cyanoacrylate adhesive (Zapit, Dental Ventures of America; Corona, CA), which in turn, was placed in a universal testing machine (LF Plus, LLOYD Instruments, Ametek Inc.; UK) for microshear bond testing. A thin wire (diameter $2 \mathrm{~mm}$ ) was looped around the resin cylinder making contact with half of the cylinder base and held flush against the resin/tooth interface. A force was applied to each specimen at a crosshead speed of 0.5 $\mathrm{mm} / \mathrm{min}$ until failure occurred. The data was converted to Mpa units and analyzed using the Kruskal Wallis test.

\section{RESULTS}

The means and standard deviations of the micro-shear bond strength for various surface treatments are illustrated in Table 1. The Kruskal Wallis test showed no significant difference among the groups $(\mathrm{p}=0,206)$. Group 4 showed the highest value $(35.68 \mathrm{MPa})$ of bond strength, and Group 1 showed the lowest value (32.24 $\mathrm{MPa}$ ).

Stereomicroscope images of the surfaces of groups are represented in Figures 1 and 4, respectively. The asidetched sample represents a relatively smooth natural surface (Figure 1). The presence of surface grinding grooves pattern (Figure 2) with the formation of smeared debris was the characteristic features of composite specimens treated by bur. A less distinct grinding grooves pattern is observed in stereomicroscope image for specimens treated by bur followed by acid etching (Figure 3). The stereomicroscope of laser treated group is characterized by a combination of macro and micro surface protrusions (Figure 4).
Table 1. Mean and standard deviation for all groups.

\begin{tabular}{|l|c|}
\hline Groups & Mean+SD \\
\hline Group 1 & $32.24 \pm 2.64$ \\
\hline Group 2 & $34.17 \pm 6.40$ \\
\hline Group 3 & $34.92 \pm 4.96$ \\
\hline Group 4 & $35.68 \pm 4.11$ \\
\hline & $\mathrm{KW}=4.57$ \\
& $\mathrm{P}=0.206$ \\
\hline
\end{tabular}

\section{DISCUSSION}

This study investigated the effects of different surface treatment methods on the bond strength of fresh composite resin bonded to aged composite resin. Composite-to-composite bonding analysis can be done by either applying shear or tensile forces in vitro. There is no consensus about which test should be used to evaluate the strength of composite-tocomposite bonding. However, a clinical argument can be made that in the repair of composite restorations, applied forces are predominantly in shear mode. ${ }^{24}$ Sano et al. ${ }^{25}$ explained that the small adhesive interface used in microtests contains fewer defects compared to those found in larger specimens. Therefore, in our study, the micro-shear test was used to evaluate the composite-to-composite bond strength.

The results of the present study showed no significant differences among the surface treatment methods. Thus, the null hypothesis was rejected.

Phosphoric acid etching is used clinically during repair procedure of resinbased composite restorations, especially when the defect involves the restoration itself, enamel and/or dentin surfaces. ${ }^{8}$ However, researchers studying composite repair have reported that phosphoric acid applied to the composite surface does not 
significantly increase repair bond strength. $^{26,27}$ These findings were consistent with our results. According to results of this study, although no significant differences were found among the surface treatment methods, the phosphoric acid treatment showed the lowest values of bond strength in the repair interface. Fawzy et al. ${ }^{8}$ and Bonstein et al. ${ }^{7}$ had examined the changes in surface topography associated with different mechanical and/or chemical surface treatment procedures and reported that the use of acid etching did not significantly change the morphological pattern of the aged composite surface. Also, the stereomicroscopic image of the acid-etch group samples demonstrated smoother surfaces than other groups (Figure 1). Moreover, the decomposition of inorganic filler particles in an acidic medium may impair adhesion between composite layers. $^{28}$

Surface roughness is a common property known to improve the general adhesion potential of a material, by promoting micromechanical retention between different components. ${ }^{29}$ Some researchers have claimed that the use of a diamond bur for surface roughening may create macro- and micro retentive features. $^{8,30}$ Grooves produced by the diamond bur grinding are shown in Figure 2. However, this surface roughness pattern produced by using a diamond bur alone did not increase the repair bond strength compared to other methods. The result of our study in consistence with Fawzy et al. ${ }^{8}$ stated that the use of mechanical grinding prior to the application of the adhesive layer did not improve the repair bond strength compared to the group in which only adhesive resin was used. In contrast to these results, Bonstein et al. ${ }^{7}$ studied the effect of varied repair protocols (no treatment, phosphoric acid, diamond bur, air abrasion, and silane primer combined with a diamond bur treatment) on repair bond strength and found that surface treatment with a diamond bur exhibited the highest bond strength.

Several composite repair studies have shown that grinding of the composite resin surfaces leads to the formation of a smear layer. ${ }^{8,31}$ Papacchini et al. ${ }^{6}$ and Hannig et al. ${ }^{32}$ reported that acid etching probably exercises a superficial cleaning effect which removes debris and grinding dust from the composite resin surface. Although the cleaning effect of acid-etching, a combined treatment with a diamond bur and acid-etching did not increase the repair bond strength when compared to the group treated with a diamond bur only. Moreover, when images of Group 2 and Group 3 were compared, it was observed that in Group 3 smear layer was reduced but not completely disappeared. This could be attributed to the limited effect of the acid etching to the superficial cleaning of the surface.

Because of well-established use of erbium lasers in dentistry, more researchers are studying their effects on dental materials. Lizarelli et al. ${ }^{33}$ claimed that if an old composite restoration is at the level of enamel surfaces, using a laser can be advantageous because the more mineralized composition makes hard dental tissue more resistant to the laser system. Thus, old composite resin can be removed while preserving the original tooth tissue. The situation is not as favorable when dentin is considered. Therefore, a laser can be a good choice for repairing old composite restorations. There are many studies that have evaluated the effects of lasers on the repair bond strength of ceramics ${ }^{34-36}$ and indirect composites. ${ }^{31}$, ${ }^{37}$ Some researchers have suggested that a laser can be considered a safe alternative mechanical surface treatment modality for laboratory composite repair procedures. ${ }^{31}$ The Er: YAG laser $(2,940 \mathrm{~nm})$ is more capable of increasing the tensile bond strength values of indirect resin bonded to ceramic surfaces than hydrofluoridric acid or air abrasion. ${ }^{37}$ This might be due to the 
presence of chemical elements, such as water and hydroxyl radicals on the surface, which may result in increased ablation of ceramic structure. ${ }^{38}$ However, the effect of Er: YAG lasers on repair bond strength of composite resins has not been sufficiently investigated. The results of this study coincide with those of Rossato et al., ${ }^{11}$ who compared the effect of diamond bur abrasion, standblasting, and different energies $(200 \mathrm{~mJ}, 300 \mathrm{~mJ}, 400 \mathrm{~mJ})$ of the Er: YAG laser on repair bond strength of composite resins. They reported no significant differences among the treatment groups. Combination of macro and micro surface protrusions produced by the Er:YAG laser are shown in Figure 4.

According to Powers et al., ${ }^{39}$ the success of a repair depends on the capability of the new composite resin surface to penetrate the surface that is being repaired. Poor wetability properties of high-viscose newly added composite necessitate the application of a low-viscose bonding agent to penetrate the microcracks and irregularities in the matrix of the preexisting composite to obtain micromechanical retention. ${ }^{31}$ Brosh et al. ${ }^{21}$ explained that bonding resin was the most effective agent for enhancing the SBS of repaired composite specimens, regardless of the surface texture created by the surface treatment. Yeşilyurt et al. ${ }^{29}$ claimed that using a bonding agent might mask the effect of surface treatments. However, the application of an adhesive resin is clinically mandatory because repair processes often include both enamel and dentine together with old composite. Therefore, we used adhesive resin in all groups. Doing so may cause a difference to occur among groups.

\section{CONCLUSION}

Within the limitations of this study, we concluded that all of the surface treatments we used showed similar repair bond strength. Treatment with a laser showed almost no differences compared to other methods. A laser did not have statistically significant difference in the repair bond strength compared to methods used in the other groups, but it should be noted that the laser presented some improvements because using it made the patient more comfortable and old composite restorations were removed conservatively. The durability of repair bond strength of treatment procedures should be evaluated in future studies.

\section{REFERENCES}

1. Foitzik M, Attin $\mathrm{T}$. Korrekturfüllung-Möglichkeiten und Durchführung. Schweiz Monatsschr Zahnmed 2004;114:1003-1011.

2. Padipatvuthikul P, Mair LH. Bonding of composite to water aged composite with surface treatments. Dent Mater 2007;23:519-525.

3. Tezvergil A, Lassila LVJ, Vallittu PK. Composite-composite repair bond strength: effect of different adhesion primers. J Dent 2003;31:521-525.

4. Vanckerckoven H, Lambrechts $P$, Van Beylen $M$, Davidson CL, Vanherle G. Unreacted methacrylate groups on the surfaces of composite resins. J Dent Res 1982;61:791-795.

5. Rathke A, Tymina $Y$, Haller B. Effect of different surface treatments on the composite-composite repair bond strength. Clin Oral Invest 2009;13:317-323.

6. Papacchini F, Dall'Oca S, Chieffi N, Goracci C, Sadek FT, Suh BI, Tay FR, Ferrari M. Composite-tocomposite microtensile bond strength in the repair of microfilled hybrid resin; effect of surface treatment and oxygen inhibition. J Adhes Dent 2007;9: 25-31.

7. Bonstein T, Garlapo D, Donarummo JJr, Bush PJ. Evaluation of varied repair protocols applied to aged 
composite resin. J Adhes Dent 2005;7:41-49.

8. Fawzy AS, El-Askary FS, Amer MA. Effect of surface treatments on the tensile bond strength of repaired water-aged anterior restorative micro-fine hybrid resin composite. J Dent 2008;36:969-976.

9. Cesar PF, Meyer Faara PM, Miwa Caldart R, Gastaldoni Jaeger R, da Cunha Ribeiro F. Tensile bond strength of composite repairs on Artglass using different surface treatments. Am J Dent 2001;14:373377.

10. Passos SP, Ozcan M, Vanderlei AD, Leite FP, Kimpara ET, Bottino MA. Bond strength durability of direct and indirect composite systems following surface conditioning for repair. J Adhes Dent 2007;9:443447.

11. Rossato DM, Bandéca MC, Saade EG, Lizarelli RFZ, Bagnato VS, Saad JRC. Influence of Er:YAG laser on surface treatment of aged composite resin to repair restoration. Laser Physics 2009;19:2144-2149.

12. Bader C, Krejci I. Indications and limitations of Er:YAG laser applications in dentistry. Am J Dent 2006;19:178-186.

13. Li J. Effects of surface properties on bond strength between layers of newly cured dental composites. J Oral Rehabil 1997;24:358-360.

14. Kupiec KA, Barkmeier WW. Laboratory evaluation of surface treatments for composite repair. Oper Dent 1996;21:59-62.

15. Ozcan M, Barbosa SH, Melo RM, Galhano GA, Bottino MA. Effect of surface conditioning methods on the microtensile bond strength of resin composite to composite after aging conditions. Dent Mater 2007;23:1276-1282.

16. Söderholm KJ, Roberts MJ. Variables influencing the repair strength of dental composites. Scand J Dent Res 1991;99:173-180.

17. Yap AU, Sau CW, Lye KW. Effects of aging on repair bond strengths of a polyacid-modified composite resin. Oper Dent 1999;24:371-376.

18. Crim GA, Garcia-Godoy F. Microleakage: the effect of storage and cycling duration. J Prost Dent 1987;57:574-576

19. Trajtenberg CP, Powers JM. Bond strengths of repaired laboratory composites using three surface treatments and three primers. Am J Dent 2004;17:123-126.

20. Bouschlicher MR, Cobb DS, Vargas MA. Effect of two abrasive systems on resin bonding to laboratoryprocessed indirect resin composite restorations. J Esthet Dent 1999;11:185-196.

21. Brosh $\mathrm{T}$, Pilo R, Bichacho $\mathrm{N}$, Blutstein R. Effect of combinations of surface treatments and bonding agents on the bond strength of repaired composites. J Prosthet Dent 1997;77:122-126.

22. Shahdad SA, Kennedy JG. Bond strength of repaired anterior composite resins: an in vitro study. $\mathbf{J}$ Dent 1998;26:685-694.

23. Gregory WA, Pounder B, Bakus E. Bond strengths of chemically dissimilar repaired composite resins. J Prosthet Dent 1990;64:664-668.

24. Rinastiti M, Ozcan M, Siswomihardjo W, Busscher HJ () Effects of surface conditioning on repair bond strengths of non-aged and aged microhybrid, nanohybrid, and nanofilled composite resins. Clin Oral Investig 2011;15:625-33.

25. Sano H, Shono T, Sonoda H, Takatsu T, Ciucchi B, Carvalho R, Pashley DH. Relationship between surface area for adhesion and tensile bond strength - evaluation of a microtensile bond test. Dent Mater 1994;10:236-240. 
26. Swift EJ Jr, LeValley BD, Boyer DB. Evaluation of new methods for composite repair. Dent Mater 1992;8:362-365.

27. Swift EJ Jr, Cloe BC, Boyer DB. Effect of a silane coupling agent on composite repair strengths. Am J Dent 1994;7:200-202.

28. Kula $K$, Nelson $S$, Kula $T$, Thompson V. In vitro effect of acidulated phosphate fluoride gel on the surface of composites with different filler particles. J Prosthet Dent 1986;56:161-169.

29. Yesilyurt C, Kusgoz A, Bayram M, Ulker MJ. Initial repair bond strength of a nano-filled hybrid resin: effect of surface treatments and bonding agents. Esthet Restor Dent 2009;21:251-260.

30. Bouschlicher MR, Reinhardt JW, Vargas MA. Surface treatment techniques for resin composite repair. Am J Dent 1997;10:279-283

31. Kimyai S, Mohammadi N, Navimipour EJ, Rikhtegaran S. Comparison of the effect of three mechanical surface treatments on the repair bond strength of a laboratory composite. Photomed Laser Surg 2010; 28 Suppl 2:S25-30.

32. Hannig $C$, Laubach $S$, Hahn $P$, Attin T. Shear bond strength of repaired adhesive filling materials using different repair procedures. J Adhes Dent 2006;8:35-40.

33. Lizarelli RF, Moriyama LT, Bagnato VS. Ablation of composite resins using Er:YAG laser--comparison with enamel and dentin. Lasers Surg Med 2003;33:132-139.

34. Akova T, Yoldas O, Toroglu MS, Uysal H. Porcelain surface treatment by laser for bracket-porcelain bonding. Am J Orthod Dentofacial Orthop 2005;128:630-637.

35. Shiu P, De Souza-Zaroni WC, Eduardo C de P, Youssef MN. Effect of feldspathic ceramic surface treatments on bond strength to resin cement. Photomed Laser Surg 2007;25:291-296.

36. Gokce B, Ozpinar B, Dundar M, Comlekoglu E, Sen BH, Gungor MA. Bond strengths of all-ceramics: acid vs laser etching. Oper Dent 2007;32:173-178.

37. Burnett LH Jr, Shinkai RS, and Eduardo Cde P. Tensile bond strength of a one-bottle adhesive system to indirect composites treated with Er:YAG laser, air abrasion, or fluoridric acid. Photomed Laser Surg 2004;22:351-356.

38. Eduardo Cde P, Bello-Silva MS, Moretto SG, Cesar PF, de Freitas PM. Microtensile bond strength of composite resin to glass-infiltrated alumina composite conditioned with Er,Cr:YSGG laser. Lasers Med Sci 2012;27:7-14.

39. Powers JM, Pratten DH, Collard SM, Cowperthwaite GF. Spreading of oligomers on polymers. Dent Mater 1991;7:88-91. 